
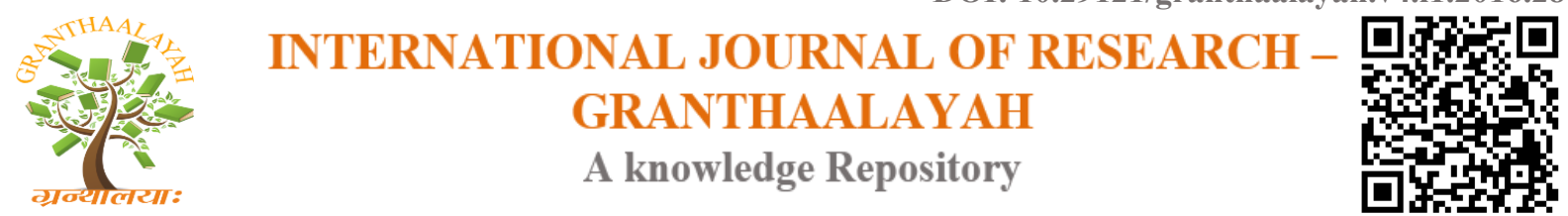

Social

\title{
AGGRESSION BETWEEN BOYS AND GIRLS INTER SCHOOL U-17 FOOTBALLERS OF MANIPUR
}

\author{
Dr. Maibam Chourjit Singh ${ }^{1}$, R. K. Nongdren Singh ${ }^{2}$ \\ ${ }^{1}$ Assistant Professor, Department of Physical Education and Sports Science, Manipur \\ University, INDIA \\ ${ }^{2}$ Research Scholar, Department of Physical Education and Sports Science, Manipur University, \\ INDIA
}

\begin{abstract}
The purpose of the current study to explore the significant difference on aggression between boys and girls footballers of Manipur. Bush and Perry Aggression Questionnaire have been administered to 50 football players (Boys $=25$ and Girls $=25$, average age is 16.5 years) participated in Subroto Mukherjee football tournament for under 17 boys and girls held at Khuman Lampak Sports Complex from 13th to 19th June 2015 are selected. The comparative Mean Scores of the boys and girls footballers on physical, hostility, anger and verbal aggression, are found to be statistically insignificant as the value obtained are 1.293, 0.257, 0.537 and 1.362 respectively whereas the tabulated $t$ - value was 2.01 with 48 degree of freedom at 0.05 level of significance.
\end{abstract}

Keywords:

Aggression, Physical, Verbal, Hostility, Anger, Football.

Cite This Article: Dr. Maibam Chourjit Singh, and R. K. Nongdren Singh, "AGGRESSION BETWEEN BOYS AND GIRLS INTER SCHOOL U-17 FOOTBALLERS OF MANIPUR" International Journal of Research - Granthaalayah, Vol. 4, No. 1 (2016): 119-124.

\section{INTRODUCTION}

Aggressiveness in general is defined as "an overt verbal or physical act that can psychologically or physically injure another person or oneself' (Husman and Silva, 1984, p. 247). Additionally, it is noted that there are two types of behaviours those we can label as aggressive. The first of these is hostile aggression and the other is instrumental aggression (Anderson and Bushman, 2002; Cox, 1994; Cratty, 1989). Hostile aggression is an impulsive behaviour, contains rage (Bushman and Anderson, 2001) and aims to harm a person psychologically or physically. In instrumental aggression, the basic motive is to achieve a certain goal.

The definition of aggression is highly contested. Aggression is typically defined by causationist researchers as "behaviour directed toward another individual carried out with the proximate 
(immediate) intent to cause harm" (C Anderson and B Bushman, 2002). There are a number of behaviours that fit into this category, including verbal aggression as well as physical harm. Aggression can be either direct (within the presence of the other individual) or indirect (behind their back). Causationist researchers Bushman and Huesmann have argued that while "aggression was an adaptive behaviour for many of our ancient ancestors", aggression today "seems mal-adaptive and destructive" (B Bushman and L R Huesmann, 2010). They noted that most social psychologists are interested in why people become aggressive and how to reduce it. Christopher Ferguson defines aggression as "behaviour that is intended to increase the social dominance of the organism relative to the dominance position of other organisms" (C Ferguson, 2010). This suggests that aggression is an instrumental behaviour which is not necessarily antisocial. Ferguson argues that the causationist definition of aggression that fails to distinguish between pro-social aggression, (which is necessary to assert oneself, engage in debate and discourse, and for success in the military, law enforcement and business) and antisocial aggression (undesirable, abnormal aggression) (C Ferguson, 2010).

Physical aggression is described as physical violence towards other people, like kicking, hitting, scratching, spitting, throwing objects, pinching, biting, pulling hair or strangling (Duxbury 2002, Secker et al. 2004, Sukhodolsky et al. 2005, Grassi et al. 2006, Foster et al. 2007). Verbal aggressive behaviour (Duxbury 2002, Foster et al. 2007, Kisa 2008) is described as verbal abuse, like threats of harm (Farrell et al. 2006, Ferns AND Meerabeau 2007), rudeness (Farrell et al. 2006), or swearing (Stone et al. 2010, Stone et al. 2011). Thus, the present study attempts to find out the significant difference on aggression between Inter School U-17 boys and girls footballers of Manipur.

\section{METHOD}

\section{SELECTION OF THE SUBJECTS}

For the purpose of the study, altogether fifty (50) football players comprising twenty five (25) each from both boys and girls are selected. The subjects are randomly selected from the participants who are coming from the different schools of Manipur for the participation in Inter School Subroto Mukherjee Football Tournament for under 17 boys and girls which is being organised by Directorate of Youth Affairs and Sports, Govt of Manipur at Khuman Lampak Sports Complex during $13^{\text {th }}$ to $19^{\text {th }}$ June 2015 . Further, the average age of the participants is 16.5 years.

\section{POPULATION OF THE STUDY}

The whole population of the present study is simply categorized in the following manner.

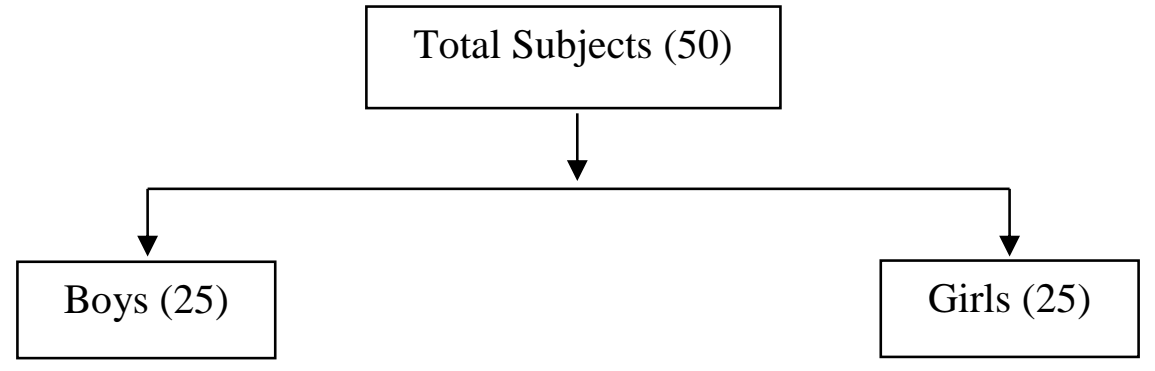




\section{SELECTION OF TOOLS}

Aggression questionnaire prepared by Buss, A. H. and Perry M. P. 1992 is used to measure the level of aggression for football players of the study population. The test is composed of 29 items on 5-point scales which include 9 items for physical aggression, 5 items for verbal aggression, 7 items for anger and 8 items for hostility. The maximum possible score which can be secured by a subject on the BPAQ (Buss and Perry Questionnaire) is 145 viz. physical aggression-45, verbal aggression- 25, anger aggression- 35 and hostility aggression- 40.

\section{DATA COLLECTION}

The data for the present are collected from both the boys and girls footballers during the tournament without disturbing their match schedule. For this, prior consent has also been taken from the organizer i.e. Directorate of Youth Affairs and Sports, Govt. Manipur as well as from the officials of the concerned team. In order to get the accurate response from the subjects, the proper instruction for the completion of the questionnaire has also been made carefully. Wherever necessary, the doubt by the subject in attempting the entire questions is also minimised.

\section{STATISTICAL TOOLS}

Statistical tools such as mean, standard deviation, standard error of mean, and t-test are employed to analyse the data accordingly. The level of significance chosen is as 0.05 .

\section{RESULTS}

The comparison between Boys and Girls football players to investigate the significant difference on BPAQ scores are statistically analyzed by using t- test. The data pertaining to the same is presented in Table 1

Table 1: Comparison of BPAQ Scores between Boys and Girls Footballers

\begin{tabular}{|l|l|c|l|l|l|}
\hline Group & $\mathbf{N}$ & Mean \pm S.D & SE $_{\mathbf{M}}$ & df & t-value \\
\hline Boys & 25 & $94.20 \pm 8.09$ & 1.61 & \multirow{2}{*}{48} & \multirow{2}{*}{1.68} \\
\hline Girls & 25 & $98.84 \pm 11.11$ & 2.22 & & \\
\hline
\end{tabular}

*Significant at 0.05 level

' $t$ ' $0.05(48)=2.01$

The maximum mean (S.D.) value of aggression score is observed in girls footballer $(98.84 \pm$ 11.11) whereas, minimum score of aggression i.e. $94.20 \pm 8.09$ is also observed in case of boys footballer. Despite slightly variation in their mean values, the insignificant difference in aggression between boys and girls footballers are found with the $t$ value as 1.68 whereas, the tabulated value is 2.01 with 48 degrees of freedom at 0.05 level of significance. 
Table 2: Comparison of Scores on Physical Aggression between Boys and Girls Footballers

\begin{tabular}{|l|l|l|l|l|l|}
\hline Group & $\mathbf{N}$ & Mean \pm S.D & $\mathbf{S E}_{\mathbf{M}}$ & $\mathbf{D f}$ & t-value \\
\hline Boys & 25 & $29.28 \pm 4.41$ & 0.88 & \multirow{2}{*}{4} & \multirow{2}{*}{1.29} \\
\hline Girls & 25 & $31.32 \pm 6.54$ & 1.30 & & \\
\hline
\end{tabular}

*Significant at 0.05 level

' $t$ ' $0.05(48)=2.01$

Table 2 highlights the Physical Aggression between Boys and Girls football players. In case of physical aggression, greater average score is found in boys footballers than that of girls footballers $(29.28 \pm 4.41,31.32 \pm 6.54)$. When utilizing $t$ - test on the average score of the physical aggression between boys and girls footballers, insignificant differences are also found between the two groups at 0.05 level of significance where, obtained value of $t=1.29$ and tabulated value of $\mathrm{t}=2.01$ with 48 degree of freedom.

Table 3: Comparison of Scores on Hostility Aggression between Boys and Girls Footballers

\begin{tabular}{|l|l|l|l|l|l|}
\hline Group & N & Mean \pm S.D & SE $_{\mathbf{M}}$ & Df & t-value \\
\hline Boys & 25 & $25.28 \pm 5.37$ & 1.07 & \multirow{2}{*}{0} & \multirow{2}{*}{0.25} \\
\hline Girls & 25 & $25.64 \pm 4.50$ & 0.90 & & \\
\hline
\end{tabular}

*Significant at 0.05 level

' $t$ ' $0.05(48)=2.01$

There is no statistical significance between the boys and girls footballers in hostility aggression as evidenced by $\mathrm{t}$ - test $(\mathrm{t}=0.25)$. Apart from this insignificant difference, the average score on hostility aggression of both the groups has been found quite similar with the values $25.28 \pm 5.37$ for boys and $25.64 \pm 4.50$ for girls.

Table 4: Comparison of Scores on Anger Aggression between Boys and Girls Footballers

\begin{tabular}{|l|l|l|l|l|l|}
\hline Group & N & Mean \pm S.D & SE $_{\mathbf{M}}$ & Df & t-value \\
\hline Boys & 25 & $22.84 \pm 3.39$ & 0.67 & \multirow{2}{*}{48} & \multirow{2}{*}{0.53} \\
\hline Girls & 25 & $23.40 \pm 3.94$ & 0.78 & & \\
\hline
\end{tabular}

*Significant at 0.05 level

' $t$ ' $0.05(48)=2.01$

The anger aggression is also one of the very important types of aggression. The application of ttest is shown in table 4 but as proven by the $t$ value i.e. 0.53 , there is no significant difference between boys and girls footballers in case of anger aggression. Whereas, the tabulated value is 2.01 with 48 degrees of freedom at 0.05 level of significance.

Table 5: Comparison of Scores on Verbal Aggression between Boys and Girls Footballers

\begin{tabular}{|l|l|l|l|l|l|}
\hline Group & $\mathbf{N}$ & Mean \pm S.D & $\mathbf{S E}_{\mathbf{M}}$ & Df & t-value \\
\hline Boys & 25 & $17.20 \pm 3.31$ & 0.66 & \multirow{2}{*}{48} & \multirow{2}{*}{1.36} \\
\hline Girls & 25 & $18.40 \pm 2.90$ & 0.58 & & \\
\hline
\end{tabular}

*Significant at 0.05 level

' $t$ ' ${ }_{0.05}(48)=2.01$ 
Statistically insignificance is also again found in the verbal aggression between the boys and girls footballers of Manipur (Inter School U- 17) as seen in the other components of aggression viz. Physical aggression, hostility aggression and anger aggression. This is incorporated with the $\mathrm{t}$ value i.e. 1.36 which is insignificant at 0.05 probability level of significance.

\section{DISCUSSION}

There is no significant difference obtained on Aggression between boys and girls footballers of Manipur especially in case of Inter School U- 17. Insignificant difference is still observed in these two groups when we examined with the different components of aggression like physical aggression, hostility aggression, angry aggression and verbal aggression. The possible reason could be explained in terms of their level of participation as they are Inter School level players. Besides, their level of competition is not too much tough in comparison to those footballers who are playing at higher tournaments. Further, the participation is opened to each and every students of different school who are deemed to be bonafide students of a concerned school where the experience footballers are limited. Hence, the aggression of boys and girls footballers of Manipur who are participating in the Inter School level could not be differentiated. Moreover, they belong to the similar category of aggression whether it is physical aggression, hostility aggression, angry aggression or verbal aggression. Therefore, it can be summarized that the significant difference on aggression between the Inter School boys and girls footballers cannot be seen in this study population.

\section{CONCLUSION}

Based on the results, the present study can be concluded in the following manners.

- There is no significant difference between boys and girls footballers (Inter School U-17) of Manipur in the various components of aggression like physical aggression, hostility aggression, angry aggression and verbal aggression.

- Thus, the overall aggression of the boys and girls footballers of Manipur especially Inter School (U-17) are not statistically significant and cannot be differentiated between them in case of aggression.

Further, it is also suggested that as the present study is carried out with the limited sample size; tools; and variables, a deep research incorporating more variables and samples may give better insight on the problem. Similar studies can also be done on different categories. The study may add a new dimension in the literature of physical education and sports sciences as well as football too.

\section{REFERENCES}

[1] Anderson, C and Bushman, B. (2002). Human Aggression 53rd Annual Review of a Psychology 27, 28.

[2] Buss, A. H. and Perry, M. P. (1992). The Aggression Questionnaire. Journal of Personality and Social Psychology, 63, 452-459.

[3] Bushman, B and Huesmann, L. R. (2010). Aggression, in S T Fiske, D T Gilbert and G Lindzey (eds), Handbook of social psychology, 833. 
[4] Duxbury, J. (2002). An evaluation of staff and patient views of and strategies employed to manage inpatient aggression and violence on one mental health unit: A pluralistic design. Journal of Psychiatric and Mental Health Nursing 9, 325-337.

[5] Ferguson, C. (2010). The Modern Hunter-Gatherer Hunts Aliens and Gathers PowerUps: The Evolutionary Appeal of Violent Video Games and How They Can Be Beneficia, in $N$ Kock, Evolutionary Psychology and Information Systems Research: A New Approach to Studying the Effects of Modern Technologies on Human Behavior, 329, 331.

[6] Ferguson, C. (2010). The Wild West of Assessment: Measuring Aggression and Violence in Video Games, "L Annetta and S Bronack (Eds), Serious Educational Game Assessment: Practical Methods and Models for Educational Games, Simulations and Virtual Worlds, 31, 37-8.

[7] Farrel, G. A., Bobrowski, C. and Bobrowski, P. (2006). Scoping workplace aggression in nursing: Finding from an Australian study. Journal of Advanced Nursing 55(6), 778-787.

[8] Ferns, T. and Meerabeau, L. 2007. Verbal abuse experienced by nursing student. Journal of Nurshing 61 (4), 436- 444.

[9] Foster, C., Bowers, L. and Nijman, H. 2007. Aggressive behaviour in acute psychiatric wards: Prevalence, severity and management. Journal of Advanced Nursing 58, 140-149.

[10] Grassi, L., Biancosino, B., Marmai, L.,Kotrotsiou, V., Zanchi, P., Peron, L., Marangoniss, C. Vanni, A. and Barbui, C. (2006). Violence in psychiatric units: a 7-year Italian study of persistently assaultive patients. Social Psychiatry and Psychiatric Epidemiology 41(9), 698-703.

[11] Kisa, S. (2008). Turkish nurses' experiences of verbal abuse at work. Archives of Psychiatric Nursing 22(4), 200-207.

[12] Secker, J., Benson, A., Balfe, E., Lipsedge, M., Robinson, S. and Walker, J. (2004).

[13] Understanding the social context of violent and aggressive incidents on an inpatient unit. Journal of Psychiatric and Mental Health Nursing 11, 172-178.

[14] Stone, T., McMillan, M. and Hazelton, M. (2010). Swearing: it's prevalence in healthcare settings and impact on nursing practice. Journal of Psychiatric and Mental Health Nursing 17, 528-534.

[15] Sukhodolsky, D.G., Cardona, L. and Martin, A. (2005). Characterizing aggressive and non-compliant behaviours in a children's psychiatric inpatient setting. Child Psychiatry and Human Development 36(2), 177-193. 